\title{
The Real Power of Artificial Markets
}

Assessing the probabilities of future events is a problem often faced by science policymakers. For example, CERN, the European laboratory for particle physics, recently had to judge whether the probability of discovering a Higgs boson was high enough to justify extending the operation of its collider (see Science, 22 Sept., p. 2014 and 29 Sept., p. 2260). At the Foresight Exchange (FX) Web site (http://www . ideosphere.com/), traders can actually bet on the outcomes of unresolved scientific questions, including whether physicists will discover the Higgs boson by 2005 . The going price of the security (0.77 as of 24 Jan) can be seen as the market's assessment of the probability of the particle's discovery. FX is only a game, run with play money (FX dollars). Empirical studies (1), laboratory investigations (2), and policy proposals (3) argue that prices of real-money securities do constitute accurate likelihoods, since traders have strong (monetary) incentives to leverage pertinent information. But can we place legitimate credence on the accuracy of FX prices, which are determined solely through competition in a play-money market game?

To an extent, yes. We find that FX prices strongly correlate with observed outcome frequencies. We collected historical price information for 161 expired securities, corresponding to questions that had been definitively answered "yes" or "no", recorded prices thirty days before expiration, sorted securities by price, and grouped them into six price ranges. The figure plots observed frequency (the actual number of "yes" securities divided by the total number) versus average price (in FX dollars) for each group. Error bars display 95\% confidence intervals, under an assumption that outcomes are independent Bernoulli trials with a uniform prior. We find similar accuracy in another play-money market called the Hollywood Stock Exchange (http://www.hsx.com/). Prices of securities in Oscar, Emmy, and Grammy awards correlate well with actual award outcome frequencies, and prices of movie stocks accurately predict real box office results.

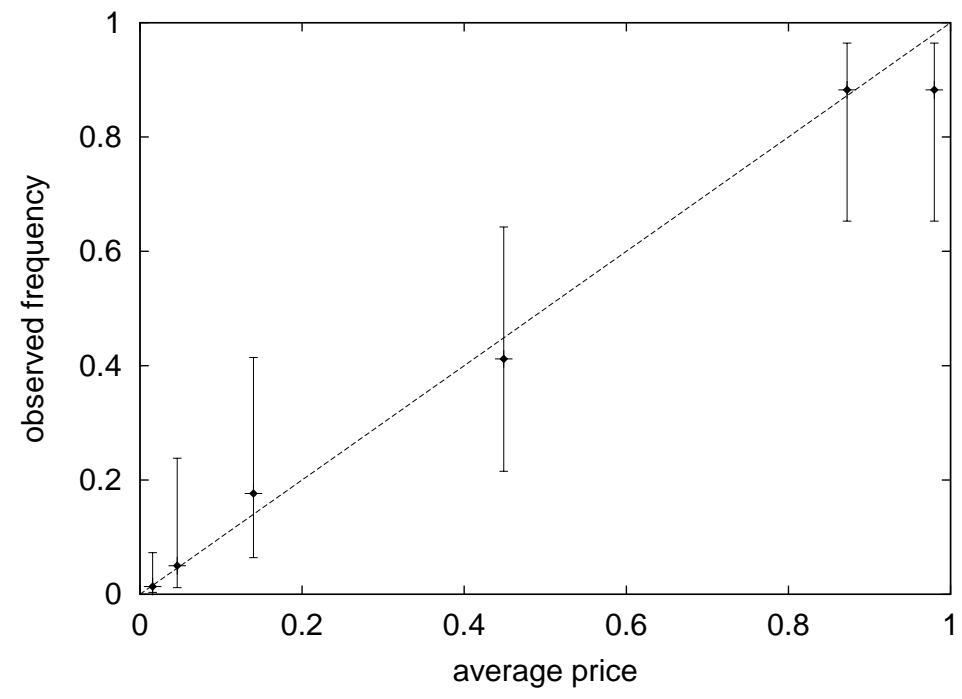

Past prices of securities in the play-money FX market accurately forecast true outcome frequencies for scientific and societal questions. 
In Science 291: 987-988, February 92001 [Letters].

\section{David M. Pennock, Steve Lawrence}

NEC Research Institute, 4 Independence Way, Princeton, NJ 08540, USA.

E-mail: \{dpennock, lawrence\}@research.nj.nec.com.

\section{Lee Giles}

School of Information Sciences and Technology and Department of Computer Science and Engineering, Pennsylvania State University, University Park, PA 16801, USA. E-mail: gi les@ ist.psu .edu.

\section{Finn Årup Nielsen}

Informatics and Mathematical Modelling, Technical University of Denmark, DK-2800 Lyngby, Denmark. E-mail: $f n @ i m m \cdot d t u \cdot d k$.

\section{References and Notes}

1. R. Forsythe, T. A. Rietz, T. W. Ross, Journal of Economic Behavior and Organization 39, 83 (1999).

2. C. R. Plott and S. Sunder, Econometrica 56(5), 1085 (1988).

3. R. D. Hanson, Social Epistemology 9(1), 3 (1995). 